\title{
Knowledge, Attitudes and Practices of Dentists on Medical Devices: Study in the Region of Dakar, Senegal
}

\author{
Kanouté Aida $^{1}$, Lo Cheikh Mouhamadou Mbacké ${ }^{1}$, Faye Daouda ${ }^{1}$, Cisse Daouda ${ }^{1}$, Diop Mbathio ${ }^{1}$, \\ Galzim Marwane ${ }^{2}$, Fall Mamadou ${ }^{3}$ \\ ${ }^{1}$ Public Health Service, Department of Dentistry, Faculty of Medicine, Pharmacy and Dentistry, University Cheikh Anta Diop, Dakar, Senegal \\ ${ }^{2}$ Department of Dentistry, Faculty of Medicine, Pharmacy and Dentistry, University Cheikh Anta Diop, Dakar, Senegal \\ ${ }^{3}$ Toxicology and Hydrology Laboratory, Department of Pharmacy, Faculty of Medicine, Pharmacy and Dentistry, University Cheikh Anta Diop, \\ Dakar, Senegal
}

\section{Email address:}

aida.kanoute@gmail.com (A. Kanouté)

\section{To cite this article:}

Kanouté Aida, Lo Cheikh Mouhamadou Mbacké, Faye Daouda, Cisse Daouda, Diop Mbathio, Galzim Marwane, Fall Mamadou. Knowledge, Attitudes and Practices of Dentists on Medical Devices: Study in the Region of Dakar, Senegal. Science Journal of Public Health.

Vol. 4, No. 5, 2016, pp. 396-400. doi: 10.11648/j.sjph.20160405.15

Received: July 20, 2016; Accepted: August 1, 2016; Published: August 21, 2016

\begin{abstract}
The aim of this study was to test the level of knowledge, attitudes and practices of the dental surgeon on medical device in the region of Dakar. This was a descriptive and cross-sectional study covering 130 dental surgeons practicing in the region of Dakar, selected following stratified sampling. One stratum grouped $60 \%$ of the sample that worked in dental public structures. Another stratum gathered $40 \%$ of the sample who were dentists working in private dental structures. More than half of the dental surgeons (53.8\%) have at least observed once an adverse effect case with a predominance of allergy (42\%). The prevailing attitude was to stop or removal of the material. However, more than $86 \%$ of the sample have never reported or notified any adverse effects following use of any material. Almost $9 / 10^{\text {th }}$ of the surveyed sample $(88.5 \%)$ have never been trained on medical device vigilance. These results strongly advocate for the integration of medical device vigilance in the current health monitoring system and for an improved awareness in notifying and spontaneously reporting adverse effects observed in the use of medical device. More than half of the dental surgeons (48.40\%) do not define the medical device vigilance.
\end{abstract}

Keywords: Medical Device, Medical Device Vigilance, Dentist

\section{Introduction}

Medical device (MD) has significantly been used in dental care or often concurrently during these last years. In some cases, these MD can even constitute the bulk of the treatment but differ from drugs by their principal mode of action other than pharmacological, immunological or metabolic; however they can contain a drug for an ancillary action [1]. Nevertheless, there are no perfect materials; when inserted into a living tissue, interactions may occur with biological systems with which they are in contact. These interactions may result in a biological response, which vary depending on the material and conditions to which it is subjected [2]. Medical device can cause unpredictable effects in the medium or long term; this could be due to mechanical defects, manufacturing or use problems. These adverse effects are common and can affect the patient's integrity. So many adverse effects implicating some MD have been reported, namely inflammatory reactions, oral or extra-oral irritations, allergies. A Norwegian study found half of the dental surgeons suffering from reported occupational health problems, such as skin diseases $(40 \%)$, eye problems, respiratory and systemic complaints (13\%) [3]. A study was conducted from 2000 to 2004 to identify common allergens associated with contact dermatitis in dental care. The most common oral manifestations were cheilitis and perioral dermatitis $(25.6 \%)$, oral lesions $(15.7 \%)$, lichenoid reactions $(14.0 \%)$, granulomatous $(10.7 \%)$ [4].

To tackle this problem, many countries have a health monitoring system for medical devices. To improve the safety of patients and practitioners, medical device vigilance serves as a monitoring station for any DM as soon as it is commercialised; this consists in the monitoring of incidents or risks of incidents 
resulting from the use of medical devices by means of preventive and /or appropriate corrective measures [5]. However in Senegal, medical device vigilance is still not integrated in the organization of health monitoring. Is health monitoring collecting a satisfactory level of information in comparison to medical device vigilance? This work is a contribution to a better understanding of medical device vigilance as well as participating in a better management of adverse reactions occurring in the use and handling of medical devices in the daily practice of dentistry. The objective of this work was to test the level of knowledge, attitudes and practices of the dental surgeon on medical device in the region of Dakar.

\section{Methods}

\subsection{Framework and Type of Study}

The investigation took place in the region of Dakar that concentrates more than half of the dentists in Senegal. There are 220 dentist offices in the region of Dakar approved by the Ministry of Health. Thirty of them are public and 190 are private. These offices are distributed into 7 districts and 31 municipalities. It was a cross sectional and descriptive study.

\subsection{Studied Population}

The studied population included a total of 264 dentists from whom 190 work in private offices and 74 in public offices in Dakar.

\subsection{Selection Criteria}

The dental surgeons included in this study were all those who have obtained the degree of Doctor of Dental Surgery, practicing at the time the survey took place and who have agreed to participate in the study. The dental surgeons who were not included in this study were all those who have refused to participate in the data collection.

\subsection{Sampling and Sample Size}

It was first to identify the location of dental offices according to districts and municipalities within the districts of the region of Dakar. Then a stratified sampling was used and 2 private and public dental offices stratums were formed. In each stratum, dental offices were drawn by simple random sampling. A number of dental offices were selected according to the calculated size. Then finally, all the dental surgeons based in the selected dental offices composed the sample with $40 \%$ of public dental surgeons and $60 \%$ of private dental surgeons. The size $\mathrm{N}$ of the sample was calculated following Schwartz formula: $\mathrm{N}=$ $(\varepsilon \alpha)^{2} \mathrm{pq} / \mathrm{I}^{2}$, applicable to cross-sectional studies, where $\varepsilon=\mathrm{Z}$ score $=1.96 ; \alpha=$ risk of error $=0.05 ; p=$ theoretical proportion of dental surgeons with a knowledge in medical device vigilance $=$ theoretically set to $50 \%$ (in the absence of specific data); $\mathrm{q}=$ the complementary probability $(=1-\mathrm{p}) \%$, I = Accuracy $=10 \%$. The use of these parameters resulted in a size of $\mathrm{N}=96$. However to deal with potential losses or unusable questionnaire and to increase the power of the study, the size was increased to 130 . Thus the study concerned 78 private dental surgeons and 52 public dental surgeons.

\subsection{Data Collection Procedures and Studied Variables}

Before starting the survey and administering the questionnaire to the dental surgeons, a pre-test on five dental surgeons was conducted which allowed to observe the reaction of the respondents to the survey, to obtain estimates of the time devoted to the various sections and to validate the questionnaire. The difficulties and ambiguities encountered were corrected in order to prepare for the final survey. The data collection took place from $12 / 05 / 2014$ to $29 / 10 / 2014$ and concerned all dental surgeons meeting the selection criteria.

The questionnaire was structured as follows:

- Variables related to sociodemographic characteristics: gender, age, specialty, workplace, years of practice, and most practiced therapeutic acts.

- Variables related to attitudes and practices of dental surgeons in relation with medical devices and their adverse effects: materials more often used, adverse effects cases, report of cases and procedures followed.

- Variables in relation to the knowledge on material device vigilance: meaning, objectives, training, existence of a notification form and the need for monitoring of medical devices after sale.

\subsection{Ethical Considerations}

Having obtained approval from the Ministry of Health and informed the person in charge of health-care facilities, a questionnaire was devised and administered directly to each dentist. Furthermore, the objectives and importance of the survey were explained to dental surgeons for their consent before administering the questionnaire.

\subsection{Data Analysis}

SPSS 18 has been used for entry and processing of the data. The results were expressed in actual number and percentage for all variables.

\section{Results}

In total of 130 dental surgeons participated in the survey.

Table 1. Dental Surgeons' Socio-demographical Characteristics.

\begin{tabular}{llll}
\hline Variables & & Number & Percentage (\%) \\
\hline \multirow{2}{*}{ Sex } & Male & 82 & 63.08 \\
& Female & 48 & 36.92 \\
Age & 25-39 years & 50 & 54.54 \\
& 40-59 years & 71 & 7.30 \\
Number of & 60 and more & 9 & 19.21 \\
years of & Less than 5 years & 25 & 19.21 \\
practice & 5-10 years & 35 & 27.02 \\
Type of & 11 and more & 70 & 53.77 \\
Dentist & Specialist & 20 & 15.38 \\
\hline
\end{tabular}

From the total sample, $63 \%$ of dentists were male. The majority of dentist were aged between 25 and 39 years and 
were general practitioner (84.62\%).

Table 2. Distribution of Dental Surgeons'most used Medical Device.

\begin{tabular}{|c|c|c|c|}
\hline \multicolumn{2}{|c|}{ Medical Devices } & \multirow{2}{*}{$\begin{array}{l}\text { Number } \\
110\end{array}$} & \multirow{2}{*}{$\begin{array}{l}\text { Percentage (\%) } \\
18.45\end{array}$} \\
\hline \multirow{5}{*}{ Prosthesis } & Irreversible hydrocolloid & & \\
\hline & Elastomer & 99 & 16.61 \\
\hline & Reversible hydrocolloid & 2 & 0.33 \\
\hline & Others & 385 & 64.61 \\
\hline & Total & 596 & 100 \\
\hline \multirow{3}{*}{ Metals } & Nickel-chrome & 95 & 68.84 \\
\hline & Others & 57 & 31.16 \\
\hline & Total & 152 & 100 \\
\hline \multirow{6}{*}{$\begin{array}{l}\text { Conservative } \\
\text { dentistry and } \\
\text { endodontic } \\
\text { (CDE) }\end{array}$} & Amalgam & 117 & 17.72 \\
\hline & Composite & 117 & 17.72 \\
\hline & $\mathrm{GIC}^{*}$ & 105 & 15.75 \\
\hline & MTA* & 05 & 0.75 \\
\hline & Others & 316 & 48.06 \\
\hline & Total & 660 & 100 \\
\hline \multirow{3}{*}{ Implantology } & Titanium & 09 & 90 \\
\hline & Others & 01 & 10 \\
\hline & Total & 10 & 100 \\
\hline
\end{tabular}

*GIC: Glass Ionomer Cement, *MTA: Mineral Trioxide Aggregate

In prosthesis, the irreversible hydrocolloids are the most used medical device $(18.45 \%)$. As regards metals, nickel-chrome was the alloy of choice for $73.08 \%$ of the sample. In CDE, amalgam and composite were the most used MD by $17.72 \%$ and in Implantology, titanium was the most used MD by $90 \%$ of the sample.

Table 3. Distribution of Adverse Effects and Dental Surgeons'Attitudes.

\begin{tabular}{llll}
\hline Medical Device and Adverse Effects & Number & Percentage (\%) \\
\hline \multicolumn{1}{l}{ Occurrence Report of Adverse Effect Cases } & 70 & 53.80 \\
& Allergy & 29 & 42.00 \\
Observed & Pain & 17 & 24.60 \\
Manifestation & Inflammation & 9 & 12.40 \\
& Infection & 4 & 05.30 \\
& Sensitivity & 11 & 15.70 \\
Dental & Removal of Material & 57 & 43.85 \\
Surgeons, & Manipulation change & 20 & 15.83 \\
Attitudes & Drug prescription & 4 & 03.80 \\
& Patient referral & 34 & 26.15 \\
\hline
\end{tabular}

70 dental surgeons (53.8\%) claimed to have been at least once faced with an adverse effect case implicating a MD in their professional practice. And Allergy was the most reported adverse effect, which affected $42 \%$ of the sample. The prevailing attitude of dental surgeons $(43.8 \%)$ was to stop and remove the material.

Table 4. Notification Procedure and Medical Device Vigilance Knowledge of the Surveyed Dental Surgeons.

\begin{tabular}{llll}
\hline Medical Device and Adverse Effects & Number & Percentage (\%) \\
\hline \multicolumn{2}{l}{ Occurrence Report of Adverse Effect Cases } & 18 & 13.80 \\
Notification & Sending letter & 06 & 03.54 \\
Procedure & Telephone & 07 & 04.00 \\
& Sending mail & 05 & 03.35 \\
Address where & Department head & 9 & 06.92 \\
notification has & Order of Dentists & 2 & 1.77 \\
been reported & Oral health department & 7 & 05.82 \\
Training in medical device vigilance & 15 & 07.6 \\
Defining & Correct answer & 10 & 26.90 \\
medical device & Wrong answer & 22 & 16.90 \\
vigilance & Don't know & 63 & 48.40 \\
\hline
\end{tabular}

From the total sample $13.80 \%$ of the surveyed sample has notified cases of adverse effects observed. Only 7 dental surgeons used the phone (4\%) and the others wrote a letter or report $(7 \%)$. More than half of the dental surgeons $(48.40 \%)$ do not define the medical device vigilance.

\section{Discussion}

\subsection{Limitations of the Study}

A total of 130 dental surgeons participated in the survey. However, we met some difficulties namely: the refusal of some dental surgeons to receive us; others required that we leave them the questionnaire so that they could fill it later; others still found it too long and had not enough time for us. This is reflected on the duration of the inquiry, which was extended. To reach the calculated size, the questionnaire was photocopied twice with no return from dental surgeons.

The study sample is indicative since the region of Dakar concentrates more than $3 / 4$ of dental structures in the country. The survey allowed studying the use of medical device by dental surgeons and assessing their level of knowledge on medical device vigilance.

\subsection{Socio-demographical Characteristics}

In this survey, $63 \%$ of dentists were male; this is representative of the source population in Senegal. The mean age was 43 years. The average number of years of practice was 13 years and 6 months. These findings are consistent with the results in Mbaye's study 2010 [6].

\subsection{The Most Used Medical Devices}

In prosthesis, although dental surgeons had a large number of impression materials, it turns out at the end of this study that irreversible hydrocolloids were the most used medical device (18.45\%), followed by elastomers $(16.61 \%)$. This can be justified by the fact that these materials have a short contact time with tissues which is certainly an advantage from a toxicological point of view [7] and by their ability to offer many use options to adapt to different clinical indications.

Reversible hydrocolloids, first elastic impression materials in dentistry, were the least used by $0.33 \%$ of the surveyed population. This is due to the handling technology and treatment time that has to be quick because there is no middle of storage satisfactory enough to preserve them over an hour [8]. As regards metals, nickel-chrome is the alloy of choice for $73.08 \%$ of the sample. According to Wataha (2002), the protective oxide layer that is formed in-between is resistant to corrosion and wear [9]. However, in literature, nickel is responsible for the majority of allergic reactions of the mucous membrane of mouth; Among 2,000,000 new patients treated each year in Orthodontics in North America, 2000 to 4000 2000 exhibit sensitivity to nickel-chromium [10]. In CDE, amalgam and composite are the most used MD by $17.72 \%$ of the sample, followed by GIC and MTA users with respectively $15.75 \%$, and $0.75 \%$. However, MTA is a material that presents many clinical indications because of its inductive capacity in 
hard tissue formation. But because of its high cost, few dentists use it $[11,12]$. In implantology, titanium is the most used MD by $90 \%$ of the sample. Probably its osseointegration and mechanical qualities like hardness, lightness and resistance justify this high level of use [13].

\subsection{Adverse Effects}

During the survey, 70 dental surgeons $(53.8 \%)$ claimed to have been at least once faced with an adverse effect case implicating a MD in their professional practice. This can be justified by their wide use in dental clinic and the fact that they remain very often in the mouth for several years. Allergy was the most reported adverse effect, which affected $42 \%$ of the sample. These allergic phenomena are frequent and their prevalence tends to increase mainly because of the diversity and proliferation of allergenic products and the high growing number of person suffering from [14]. In reality, the WHO as the 4th pathology currently considers allergy in term of prevalence [15]. The prevailing attitude of dental surgeons $(43.8 \%)$ in front of observed adverse effects cases was to stop and remove the material, for more caution.

In Diouf's 2013 study on pharmacovigilance, the major part of the dentists $(77 \%)$ had the same idea to stop and change medication in case of adverse reaction [16]. Because of the frequency of occurrence of more or less serious undesirable effects, the major part of dentist respondents found that DM can be dangerous and that their monitoring after placing on the market was essential.

\subsection{Medical Device Vigilance and Dental Clinic}

The study showed that only $56.9 \%$ of the dentists know what a sheet of notification is. These figures are above those obtained among $50.4 \%$ of physicians at the UMC of Ibadan in Nigeria [17]. Although efforts have been made at the level of health programs in Senegal, a lack of awareness is noted in the oral health sector. Indeed, $86.02 \%$ of the surveyed sample has never notified cases of adverse effects observed. This figure is confirmed by results obtained in similar studies carried out by Aziz et al (2007) in Malaysia and Qing et al (2004) in China for other health professionals where $81.4 \%$ and $62.1 \%$ respectively did not report cases although suspecting them as adverse effects [18, 19]. The non-declaration of these adverse effects, or even under notification, is one of the main obstacles to the smooth running of alert programs. This is a common problem to all countries. In developed countries, such as China, a high level of under-reporting is recorded [19]; in Italy doctors had little information concerning adverse effects as well as their systems of notification [20]. Uppsala Monitoring Centre (UMC, WHO) in Sweden, which holds the international database, has got approximately 4.7 million cases of adverse reactions reported from 96 national centres. Despite this number, it is estimated that only 6 to $10 \%$ of serious adverse reactions are reported [21]. This under notification delays signal detection and under-estimates the magnitude of the problem. And Mirbaha et al (2015), are detected several barriers, such as lack of knowledge of what should be reported, fear of punishment and criticism, lack of time, lack of teamwork...[22]. These are confirmed by results obtained in study carried out by Polisena et al (2015) findings who indicated that fear of punishment, uncertainty of what should be reported and how incident reports will be used and time constraints to incident reporting are common barriers to incident recognition and reporting [23]. However, according to dental surgeons, this non-reporting of adverse events could be explained by the absence of means of notifications; only 7 dental surgeons used the phone (4\%) and the others wrote a letter or report; the remaining had no idea of notification procedures and none of the dental surgeons had a declaration form for the adverse effects of DM. Education, training and the implementation of registries were discussed as important initiatives to improve medical device surveillance in clinical practice [24].

\section{Conclusion}

The prevailing attitude was to stop or removal of the material. However, more than $86 \%$ of the sample have never reported or notified any adverse effects following use of any material. Almost $9 / 10^{\text {th }}$ of the surveyed sample (88.5\%) have never been trained on medical device vigilance.

These results advocate for the integration of medical device vigilance in the health monitoring system and improving awareness in notification and spontaneous reporting of cases of adverse effects observed. In addition, developing a notification form will facilitate reporting adverse effect cases with an improved monitoring of medical devices.

\section{References}

[1] Agence Nationale de Sécurité du Médicament et du produit de santé (ANSM). Bilan des règles applicables à la sécurité des dispositifs médicaux et propositions d'améliorations. France 2012. 76p.

[2] Lemons JE. Dental implant biomaterials. J Am Dent Assoc. 1990; 121(6): 716-19.

[3] Indumathi Sivakumar. Occupational health hazards in a prosthodonti practice: review of risk factors and management strategies. The journal of advanced prosthodontics. 2012; 4: 259-65.

[4] Khamaysi Z. Positive patch test reactions to allergens of the dental series and the relation to the clinical presentations. Contact Dermatitis. 2006; 55 (4): 216-18.

[5] Legman P. La matériovigilance dans notre pays. J Radiol. 1997; 78: 1223-27.

[6] Mbaye S. Évaluation des besoins en prothèse dentaire dans les cabinets dentaires au Sénégal. Thèse de Chirurgie Dentaire, Dakar, 2010, $\mathrm{n}^{\circ} 101$.

[7] Baker P S, Plummer K D, Parr G R, Parker M H. Dermal and mucosa reactions to an antimicrobial irreversible hydrocolloid impression material. Prosthet Dent. 2006; 95: 190-3. 
[8] Schleier P E, Gardner F M, Nelson S K, Pashley D H. The effect of storage time on the accuracy and dimensional stability of reversible hydrocolloid impression material. J Prosthet Dent. 2001; 86: 244-250.

[9] Wataha JC. Alloys for prosthodontic restorations. J Prosthet Dent. 2002; 87 (4): 351-63.

[10] Arenholt D, Bindslev. Material-related adverse reactions in orthodontics. First Edition Pocket dentistry Danmark 2012. $10 \mathrm{p}$.

[11] Beslot A, Lasfargues JJ. Mineral trioxide aggregate MTA: materiau d'apexification. Inf Dent. 2004; 35: 2263-73.

[12] De Deus G, Ximenes R, Gurgel Filho ED et al. Cytotoxicity of MTA and portland dement on human ECV 304 endothelial cells Int Endod J. 2005; 38(9): 604-09.

[13] Wennerberg A, Ide-Ektessabi A, Hatkamata S. Titanium release from implants prepared with different surface roughness. Clin Oral Implants Res. 2004; 15(5): 505-12.

[14] Ghestin JS. L'allergie en chirurgie dentaire (mécanismes, reactions étiologies). Thèse en Chirurgie dentaire, Lille 2012, Bibliogr. f. 82-85.

[15] Institut Thématique: Immunologie - Hématologie Pneumologie Allergie immuno - Dermatite atopique. Enjeux médicaux. France 2010. 105p.

[16] Diouf M, Bodian S, Lo CMM et al. Pharmacovigilance chez le chirurgiens-dentistes: enquête dans la région de Dakar, Sénégal. Santé Publique. 2013; 25: 69-76.

[17] Enwere O, Okezie and Fawole Olufunmilayo. Adverse drug reaction reporting by physicians in Ibadan, Nigeria. Pharm. Drug Saf. 2008, 17: 517-22.
[18] Aziz Z, Siang TC, Badarudin NS. Reporting of adverse drug reactions predictors of under-reporting in Malaysia. Pharm. Drug Saf. 2007; 16: 223-28.

[19] Li Q, Zhang SM, Chen HT, Fang SP, Yu X, Liu D, Shi LY, Zeng FD. Awareness and attitudes of healthcare professionals in Wuhan, China to the reporting of adverse drug reactions. Chin Med J (Engl). 2004; 117: 856-61.

[20] Cosentino M, Leoni O, Banfi F, Leechini S, Frigo G. Attitudes to adverse drug reaction reporting by medical practitioners in a Northern Italia district. Pharmacol Res. 1997; 35: 85-8.

[21] Gonzalez LE, Herdeiro MT, Figueiras A. Déterminants de la sous déclaration des effets indésirables: réactions aux médicaments: un examen systématique. Drug Saf 2009; 32: 19-31.

[22] Mirbaha F, Shalviri G, Yazdizadeh B, Gholami K, Majdzadeh R. Perceived barriers to reporting adverse drug events in hospitals: a qualitative study using theoretical domains framework approach. Implement Sci. 2015; 10: 110.

[23] Polisena J, Gagliardi A, Urbach D, Clifford T, Fiander M. Factors that influence the recognition, reporting and resolution of incidents related to medical devices and other healthcare technologies: a systematic review. Syst Rev. 2015 Mar 29; 4: 37.

[24] Polisena J, Gagliardi A, Clifford T. How can we improve the recognition, reporting and resolution of medical device-related incidents in hospitals? A qualitative study of physicians and registered nurses. BMC Health Serv Res. 2015; 15: 220. 